\title{
Primer trasplante cardíaco en Chile: el relato de un observador de primera línea
}

\author{
Eduardo Bastías \\ Médico cardiólogo \\ Profesor de Medicina Universidad Andrés Bello, \\ Académico correspondiente Academia Chilena de Medicina, Ex Jefe Cardiología Hospital Naval de Valparaíso (1968-1976).
}

A las 12.15 horas del 28 de Junio de 1968, en el Hospital Naval Almirante Nef de Valparaíso - según consta en manuscrito del Libro de Novedades del establecimiento - se dio inicio a la primera intervención en Chile de un trasplante Cardíaco.

El comienzo de la intervención significó la cristalización del proyecto programado, desde el día siguiente al primer trasplante cardíaco en seres humanos, efectuado por Christian Barnard en Ciudad del Cabo, Sudáfrica, en diciembre de 1967. El doctor Alejandro Peirano, primer ayudante del equipo quirúrgico cardiovascular, relata que, en cuanto se enteraron de la hazaña de Barnard, el Dr. Jorge Kaplán expresó "nosotros vamos a estar en eso mismo en poco tiempo más".

A partir de esa fecha comenzaron reuniones vespertinas en el domicilio del Dr. Kaplán, en Calle Álvarez, de Viña del Mar, donde se constituyó un grupo de seis cirujanos y una anestesista, para programar prácticas en perros, en dependencias de Cirugía experimental del Hospital Naval y en cadáveres, en el departamento de Anatomía Patológica del Hospital Carlos van Buren, de Valparaíso.

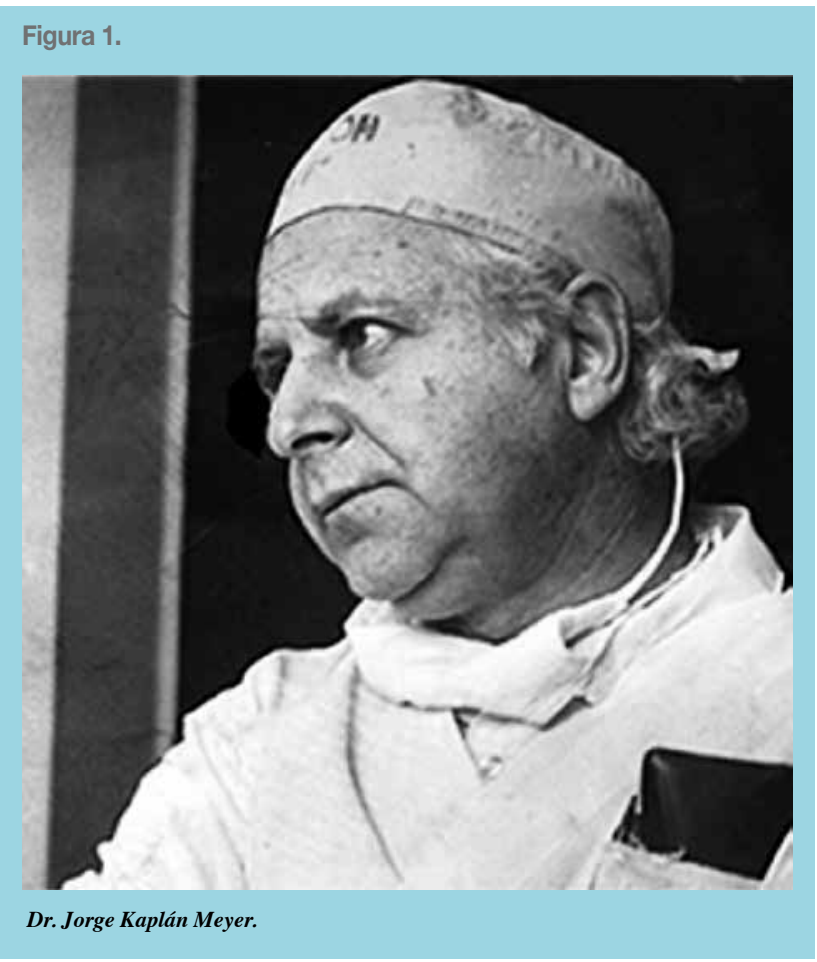




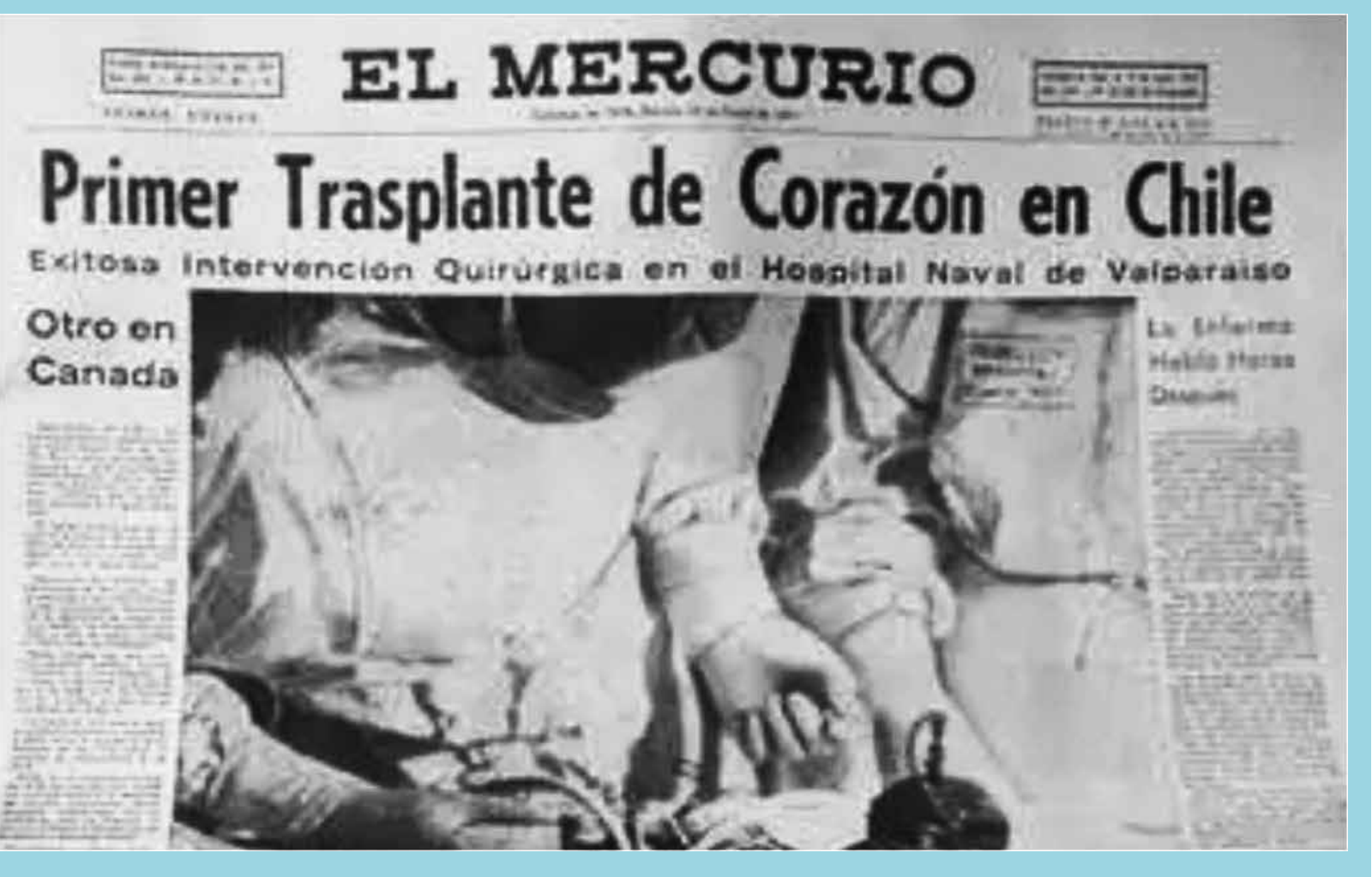

Avanzada la tarea se incorporó al Dr. Jorge Alvayay, pionero de la cardiología en la región de Valparaíso, quien integró el primer Directorio de la Sociedad Chilena de Cardiología y Cirugía Cardiovascular, y fue designado académico correspondiente de la Academia Chilena de Medicina. Su misión sería buscar la disposición de un paciente con insuficiencia cardíaca terminal.

Como el doctor Alvayay no pertenecía a la Armada, se sumó al internista Dr. Hernán Aguirre, quien asumiría como médico tratante del paciente trasplantado, contando con asesoría de los cardiólogos.

Para los controles inmunológicos se integró al bioquímico Nicolás Adriazola y para los aportes hematológicos al Jefe del Banco de Sangre del Hospital Naval, doctor Raúl Eberhard.

Tras seis meses de preparación, tenían el consentimiento de una paciente con insuficiencia cardíaca avanzada, que escapaba a una cirugía reparadora, María Elena Peñaloza Morales, de 24 años, natural de Panquehue, poblado de la Quinta región, quien padecía de una cardiopatía reumática polivalvular, con gran cardiomegalia y severas limitaciones.

El 28 de junio de 1968, se dispuso del corazón de un donante, el joven Gabriel Véliz, de 21 años, operario de un

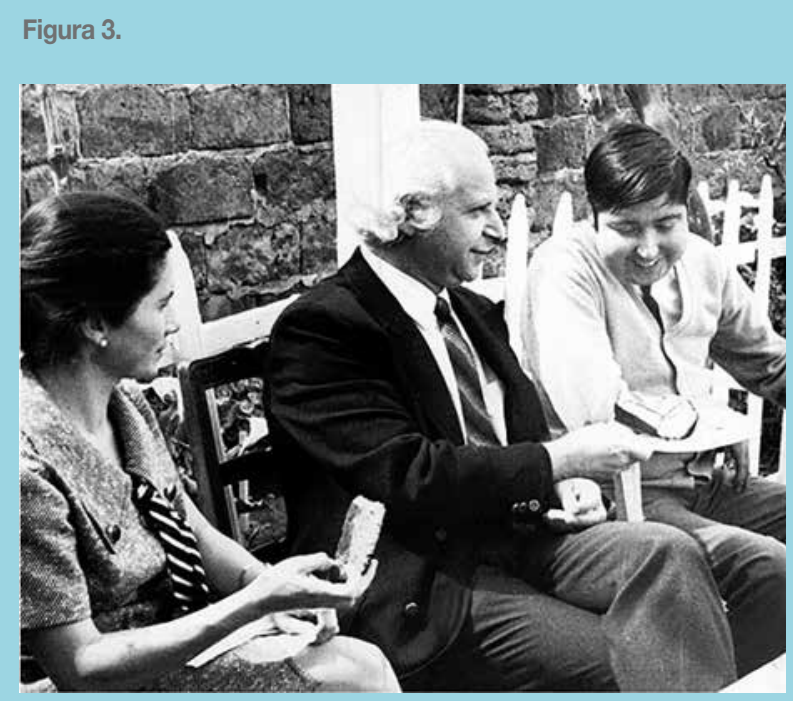

Dra. Carmen Luz González, Dr. Jorge Kaplán, Nelson Orellana.

taller mecánico, declarado con muerte cerebral.

La intervención se realizó en dos pabellones del sector antiguo del Hospital Naval. En el pabellón del donante participaron los doctores Elías Bitrán, Hernán Orellana y Gregorio Cenitagoya, que se habían capacitado para la extracción del corazón. En el pabellón principal, los doc- 
Figura 4

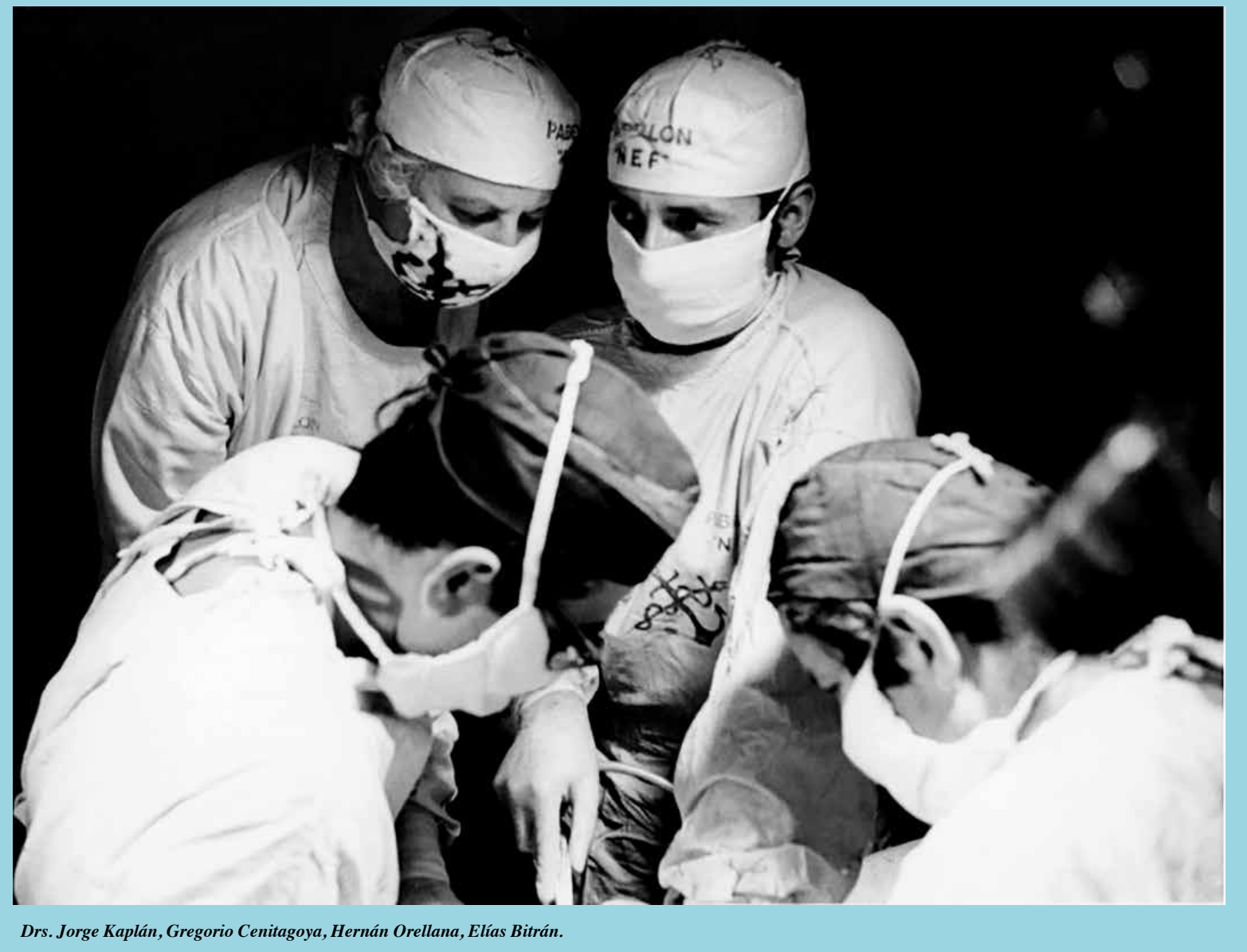

Figura 5

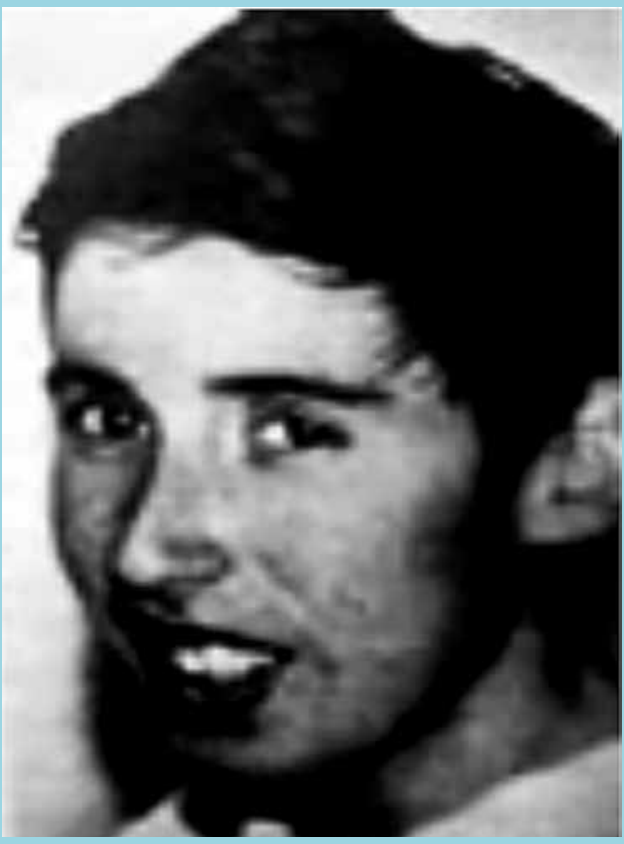

Nelson Orellana tores Jorge Kaplán, Alejandro Peirano y Gustavo Cerón preparaban el campo quirúrgico para la implantación del órgano en María Elena Peñaloza. La doctora Carmen Luz González cumplía funciones de anestesista y a cargo de la perfusión extracorpórea, con un equipo de enfermeros navales.

A través de una cúpula de vidrio, en la parte alta del quirófano, pudimos observar el delicado proceso, llevado a término con la técnica quirúrgica de Norman Shumway, la misma aplicada por Christian Barnard en Ciudad del Cabo.

María Elena Peñaloza sobrevivió 133 días, con notable mejoría en calidad de vida, siendo la segunda mujer en el mundo receptora de un corazón humano. Su trasplante cardíaco fue el primero en Chile, vigésimo tercero en el mundo y el tercero en Sud América. Falleció de una embolia cerebral.

Al mes siguiente, entre los días 14 y 17 de Julio de 1968, el equipo fue invitado a participar en el "Primer Simpo- 


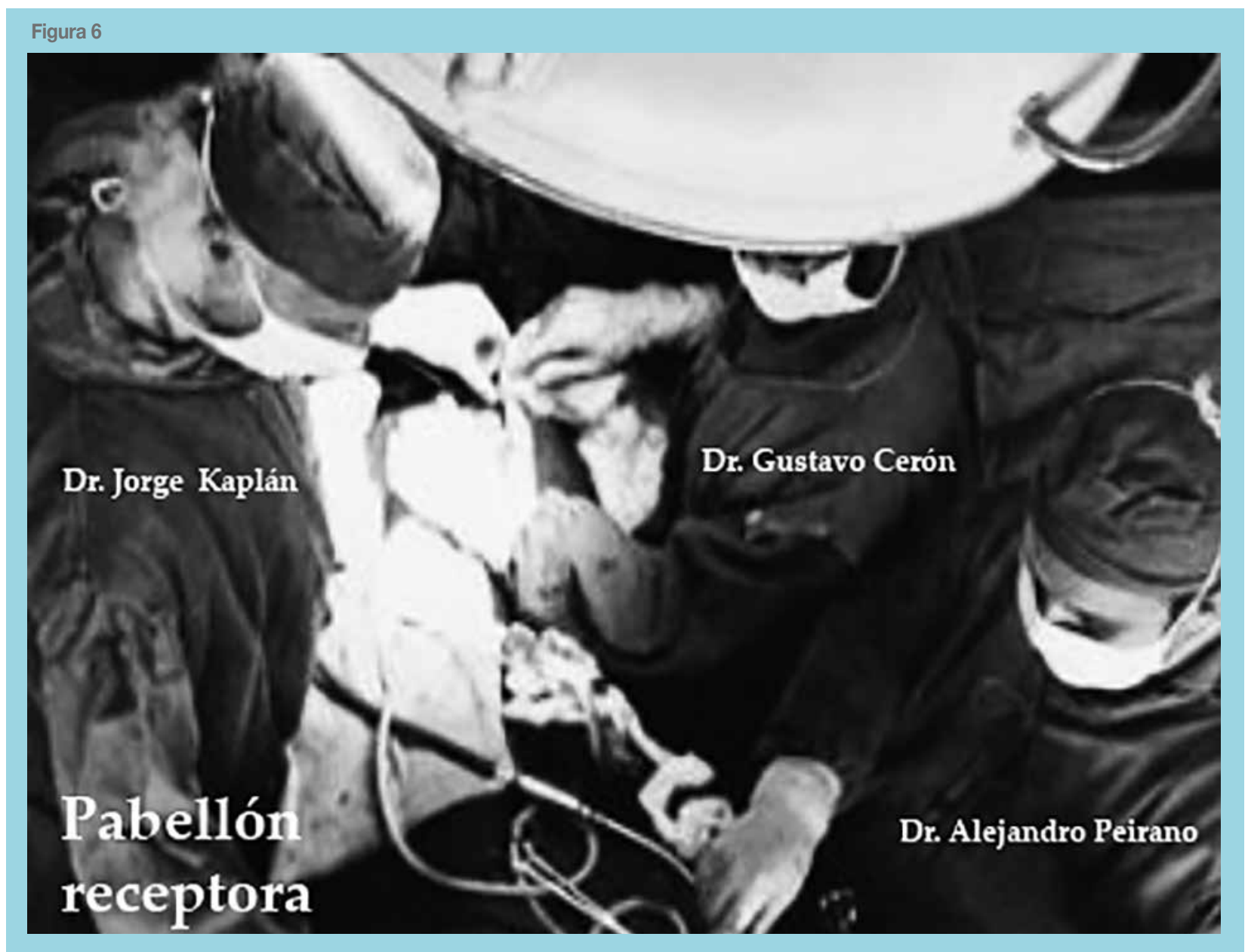

sio de Trasplante de Corazón", efectuado en Ciudad del Cabo. Allí tuvieron oportunidad de conocer un nuevo medicamento anti rechazo, el Suero Antilinfocitario. En esa fecha los pacientes trasplantados eran sometidos a tratamiento con Azatioprina y altas dosis de prednisona. El suero antilinfocitario abría la posibilidad de emplear este nuevo recurso, fabricado en Alemania, cuando había indicios de alto riesgo de rechazo. El doctor Peirano fue invitado por Christian Barnard para permanecer en su servicio hasta la llegada de un nuevo envío de la droga, para aporte al tratamiento de los pacientes en Chile.

Sólo cuatro meses más tarde del primer trasplante, el equipo del Hospital Naval de Valparaíso hizo una segunda intervención con éxito, en el receptor Nelson Orellana, joven de 20 años, procedente de la Comuna de Curacaví, quien también padecía de una insuficiencia cardíaca avanzada de origen reumático. Orellana llegó a ser el quinto mayor sobreviviente en el mundo, al fallecer de un paro cardíaco tres años y seis meses después de la intervención.
El Hospital Naval de Valparaíso en los años sesenta contaba con cirugía cardiovascular convencional y recursos limitados. No disponía de Unidad de Cuidados Intensivos ni de drogas anti rechazo efectivas. Contaba, en cambio, con el doctor Jorge Kaplán Meyer, un líder excepcional que supo organizar un equipo de alta calidad técnica y humana, para quienes los desafíos fueron crear lo que faltaba para cumplir sus objetivos.

El Dr. Kaplán falleció en Viña del Mar el 14 de abril de 2009, dejando como huella una trayectoria ejemplar. Tras titularse en la Universidad de Chile en el año 1951, se trasladó a Valparaíso para integrarse al equipo de Cirugía Cardiovascular del Hospital Carlos van Buren, que encabezaba el Dr. Pedro Uribe Concha, con los doctores Svante Törnvall y Carlos Patillo. Su primera publicación, con Bruno Günther, fue "Cirugía con hipotermia y fibrilación ventricular". Con parte del equipo se trasladó al Hospital Sanatorio Valparaíso y más tarde fue llamado para crear el Departamento de Cirugía Cardíaca en el Hospital Naval Almirante Nef, de Valparaíso. Durante 


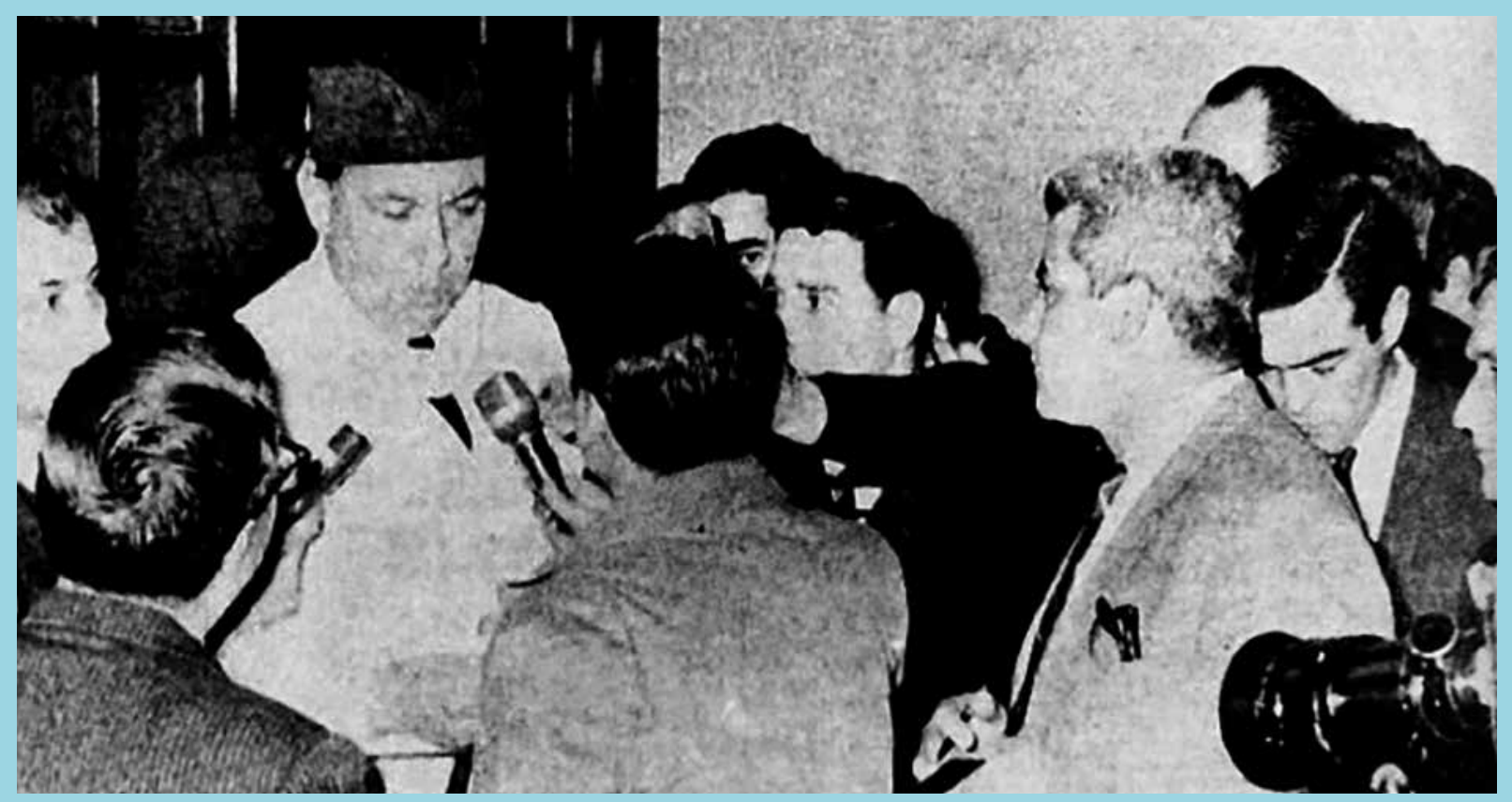

"Señores: me alegra decirles que el trasplante ha sido un éxito...".

Dr. Norman Mc Cowley, Relacionador público de Sanidad Naval.

su gestión se desarrolló la cirugía valvular, de algunas cardiopatías congénitas, implantación de marcapasos e inicio de la cirugía coronaria. Tras su jubilación de la Armada, fue invitado para integrase al Departamento de Cirugía Cardiovascular creado por el cardiólogo Jorge
Bartolucci y el cirujano Carlos Órfali, en el Hospital Dr. Gustavo Fricke, en el nuevo Servicio de Salud Viña del Mar Quillota. Allí contribuyó al desarrollo de los trasplantes cardíacos, hasta consolidación de este establecimiento como Centro de referencia nacional.
Figura 8

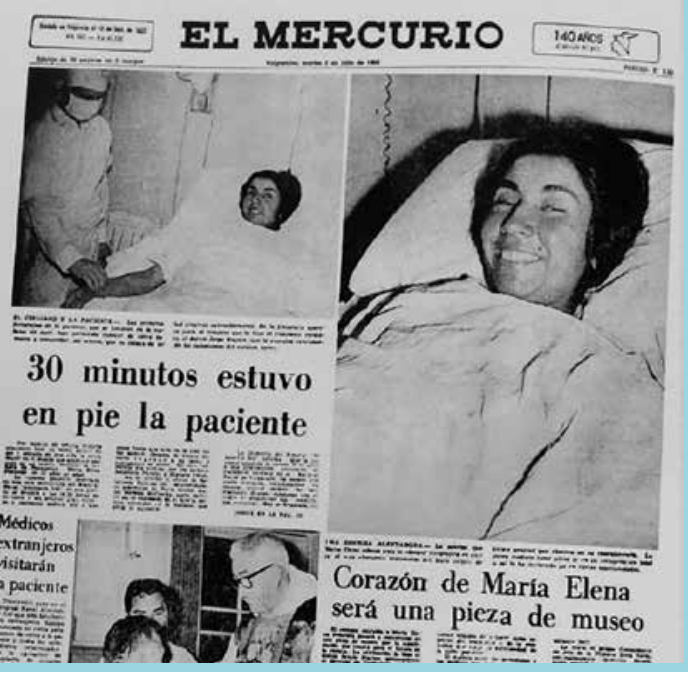

Figura 9

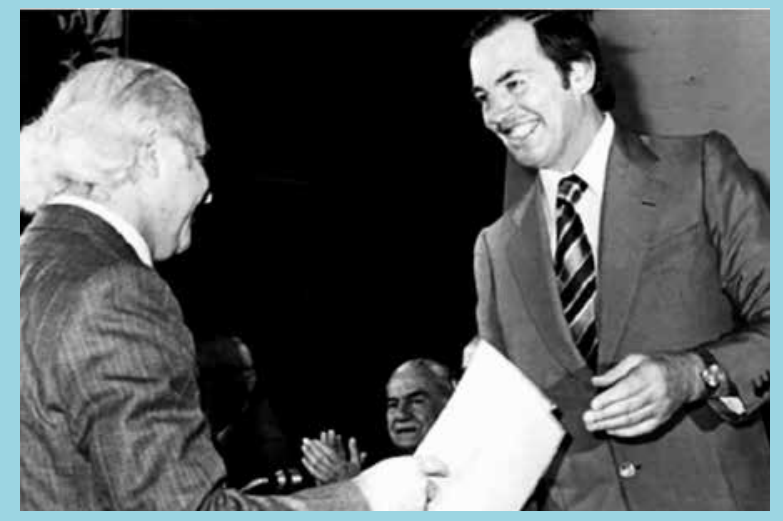

Congreso Nacional Sociedad de Cirujanos de Chile 1979, Dr. Jorge Kaplán, Dr. Christian Barnard. 
Primer trasplante cardíaco en Chile..

Bastías $E_{\text {., et al. }}$

Figura 10

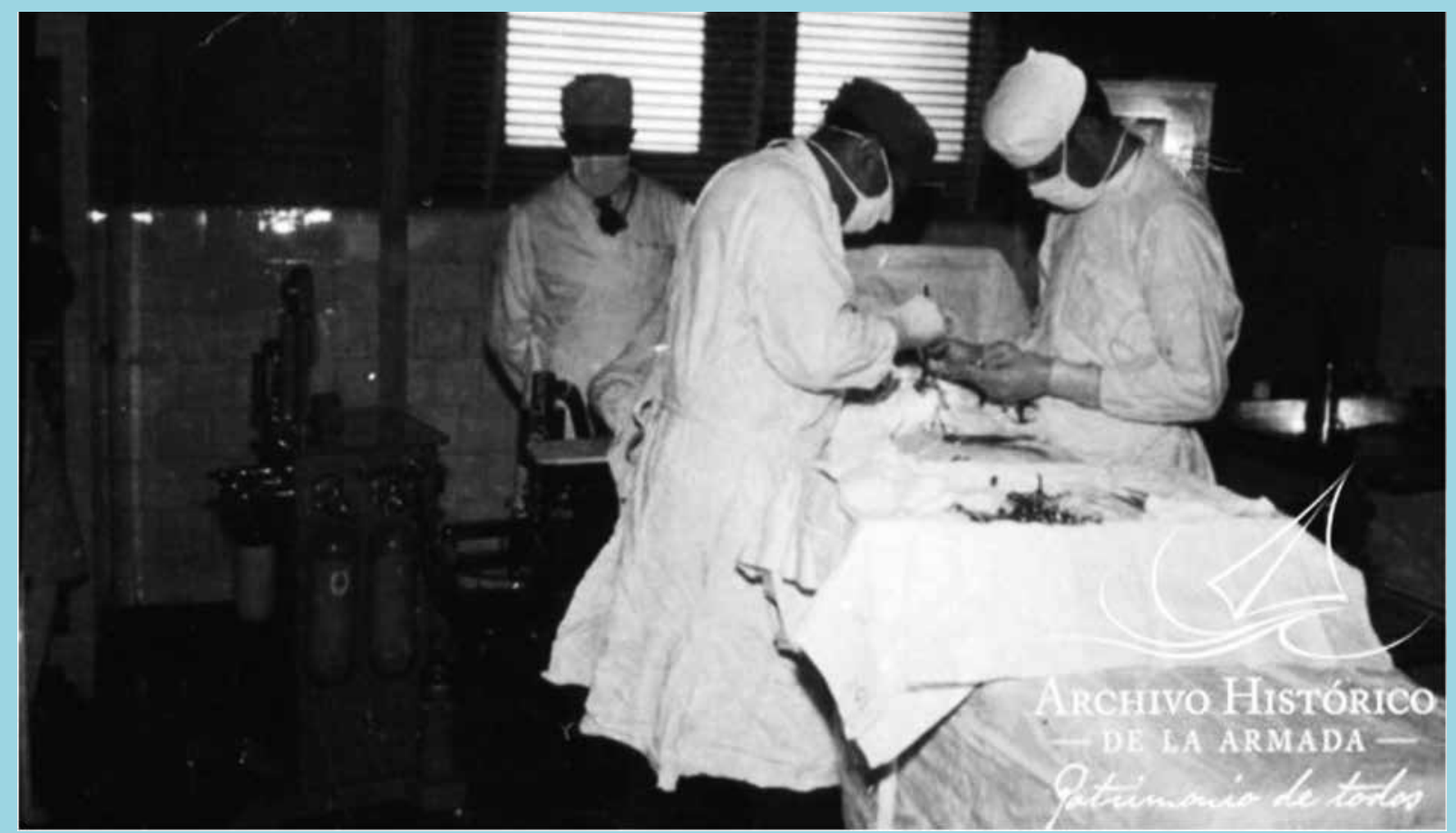

Pabellón quirúrgico del Hospital Naval Almirante Nef, en los años 60.

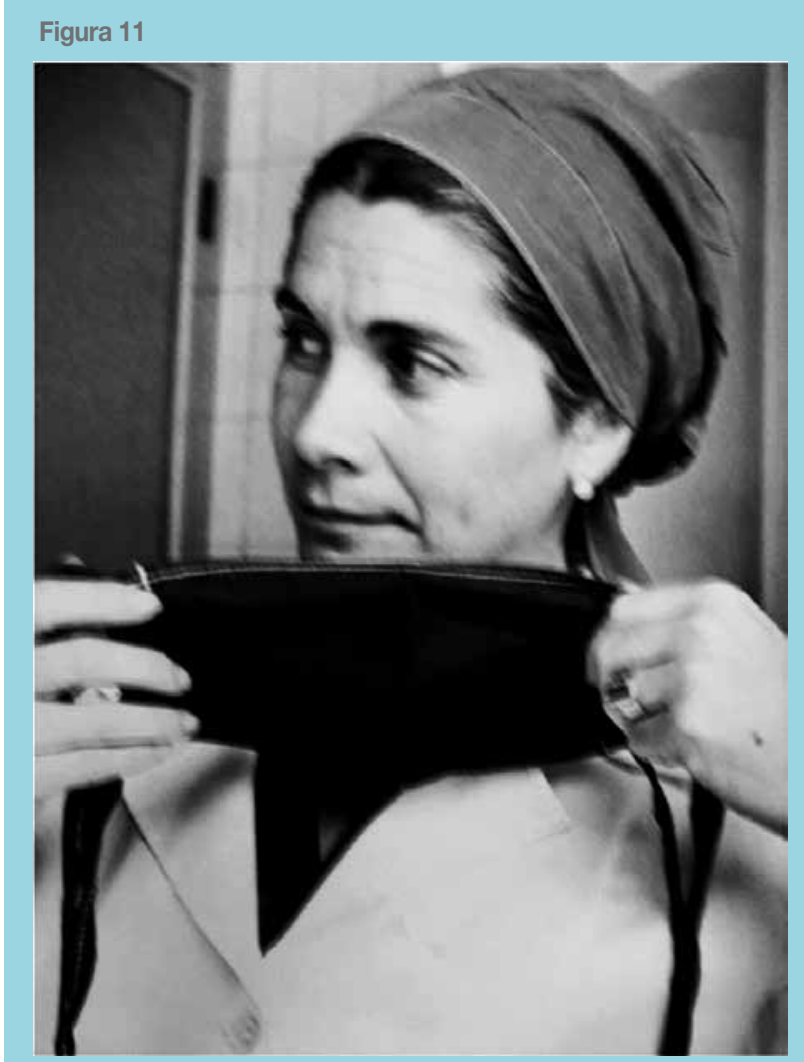

Dra. Carmen Luz González, anestesista y perfusionista.
Figura 12

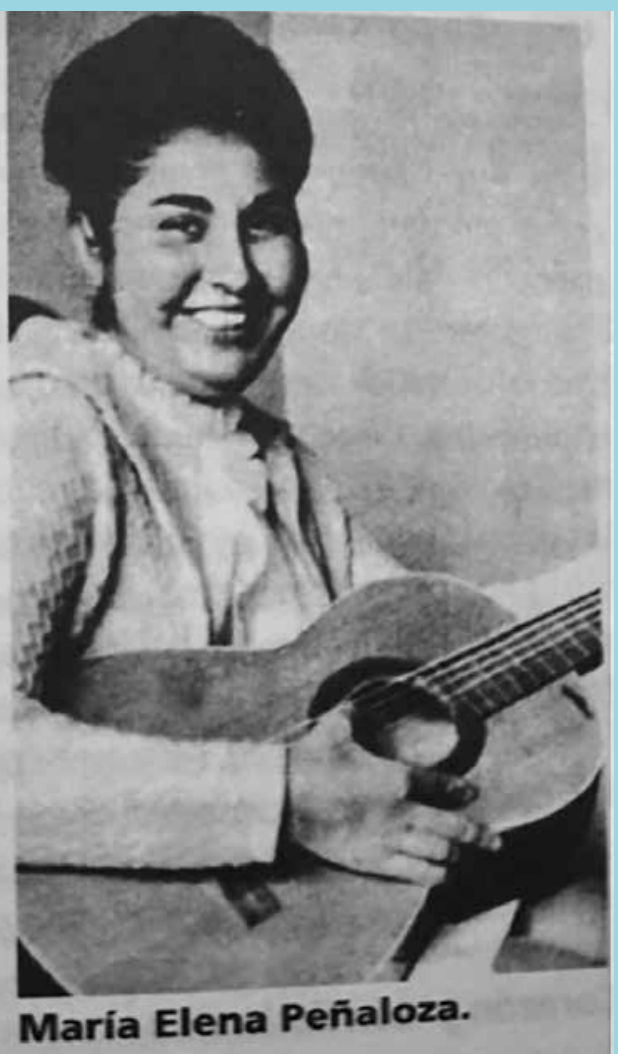




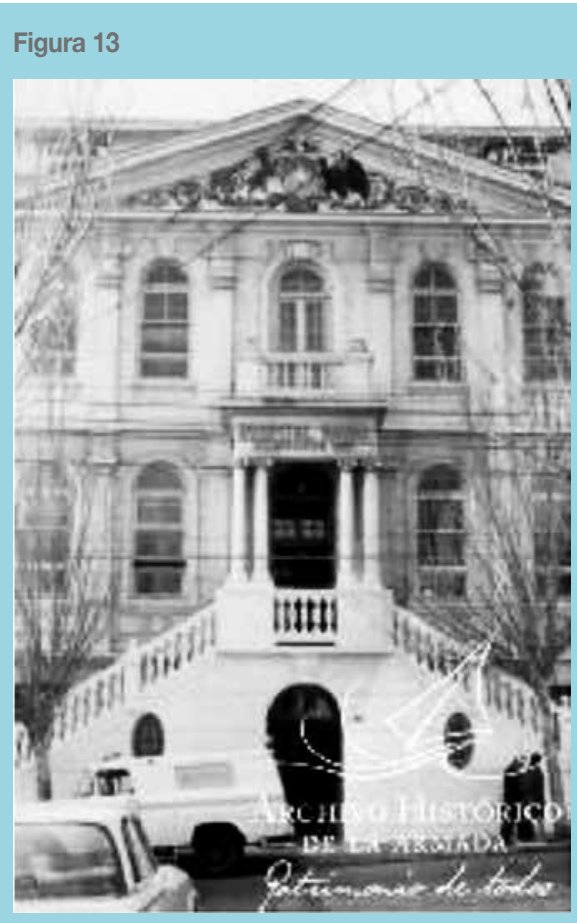

Hospital Naval Almirante Nef, Valparaíso, hacia 1960.
Figura 14

\section{MERCURIO}

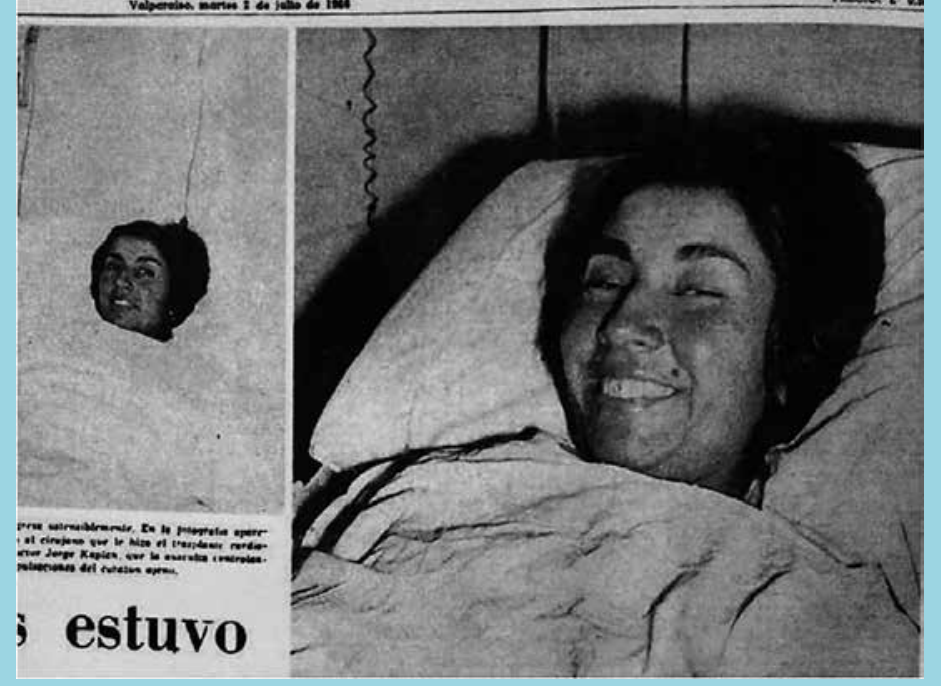

María Elena Peñaloza. 